\title{
Whistle variability in South Atlantic spinner dolphins from the Fernando de Noronha Archipelago off Brazil
}

\author{
Fernanda S. Camargo \\ Instituto de Biociências, Universidade de São Paulo, Rua do Matão, travessa 14, no 321, São Paulo, SP, \\ 05508-900, Brazil \\ Mario M. Rollo, Jr. ${ }^{\text {a) }}$ \\ Universidade Estadual Paulista, Campus do Litoral Paulista, Pça. Infante Dom Henrique s/n, São Vicente, \\ SP, 11330-205, Brazil \\ Viviana Giampaoli \\ Departamento de Estatística, Instituto de Matemática e Estatística, Universidade de São Paulo, \\ Rua do Matão 1010, São Paulo, SP, 05508-090, Brazil \\ Claudio Bellini \\ Projeto TAMAR, R. Dr. Luiz Inacio Pessoa de Melo 81/2051, Recife, PE, 51030-320, Brazil
}

(Received 9 March 2006; revised 17 July 2006; accepted 13 September 2006)

\begin{abstract}
A series of quali- and quantitative analyses were conducted to evaluate the variability of spinner dolphin whistles from the Fernando de Noronha Archipelago off Brazil. Nine variables were extracted from each whistle contour, and the whistle contours shapes were classified into the seven categories described in Driscoll (1995). The analysis showed mean beginning and ending frequencies values of 10.78 and $12.74 \mathrm{kHz}$, respectively. On average, whistle duration was relatively short, with mean values around $0.495 \mathrm{~s}(N=702)$. Comparative analyses were also conducted to investigate the relationship between the obtained results and those presented in previous studies. When comparing averages, the results of the study of Oswald et al.(2003) in the Tropical Eastern Pacific (TEP) presented less significant differences in relation to this study; only whistle duration differed significantly between both works. The results of multivariate classification tests also pointed TEP population as the closest related to the population studied here. The similarities between such disjunct populations might be attributed to a more recent isolation event (the closing of the Panama Isthmus) than the divergence that has driven North and South Atlantic populations apart. (C) 2006 Acoustical Society of America. [DOI: 10.1121/1.2359704]
\end{abstract}

PACS number(s): 43.80.Ka, 43.80.Ev, 43.80.Cs [WWA] Pages: 4071-4079

\section{INTRODUCTION}

The spinner dolphin, Stenella longirostris (Gray, 1828), is a cosmopolitan cetacean found in tropical, subtropical, and less frequently, in warm temperate waters (i.e., Norris et al., 1994). This wide distribution is followed by a notable geographic variation in several morphological characters (i.e., Akin, 1988; Douglas et al., 1992; Perrin and Dolar, 1996; Van Waerebeek et al., 1999) and ecological parameters (Barlow, 1984; Perryman and Westlake, 1998; Perrin et al., 1999). Four subspecies are currently acknowledged (Perrin, 1990; Perrin et al., 1991, 1999): Stenella longirostris longirostris, S. l. orientalis, S. l. centroamericana, and $S$. $l$. roseiventris.

Spinner dolphins, as well as other species of oceanic dolphins, emit clicks and whistles of pure tones, besides a diversified repertoire of pulsed signals (Herman and Tavolga, 1980; Norris et al., 1994; Lammers et al., 2003). Whistles have been characterized in terms of their instantaneous frequency as a function of time (i.e., spectrograms), which is

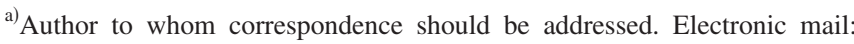
mario.rollo@csv.unesp.br
}

also referred to as a whistle contour. Some authors have studied whistles using subjective classification of their contours, and others have extracted frequency and time parameters from these contours (Bazúa-Durán and Au 2002). The function of whistles in the odontocete communication process has been extensively discussed (Tyack, 1998; McCowan and Reiss, 1995, 2001), and they seem to play an important role in the maintenance of social cohesion and in group organization (Norris et al., 1994; Janik, 2000; Janik and Slater, 1998; Lammers et al., 2003). However, the biological meaning of each frequency and time parameter, as well as of any contour category still needs to be understood (McCowan and Reiss, 1995; Bazúa-Durán and Au, 2002).

Qualitative and quantitative variations in acoustic emissions or phonations, as suggested by Bazúa-Durán and Au, (2002) were recognized and described for S. longirostris, but all studies on this variability were developed with populations from the Pacific Ocean (e.g., Norris et al., 1994; Driscoll, 1995; Wang et al. 1995a; Bazúa-Durán and Au, 2002). The only work on phonations with a population from the Atlantic Ocean were conducted by Steiner (1981), and aimed to compare different species, excluding any kind of intraspecific analysis. From this scenario, one could note that 
it is still necessary to search for any relation between all the information available in the literature, and consequently for a better understanding of the variation within and between populations.

Wang et al. (1995a), Driscoll (1995), and Bazúa-Durán and $\mathrm{Au}$ (2002) recorded spinner dolphins from Hawaii. However, their results showed significant statistical differences. Some possible reasons for these differences could be differences in the upper frequency limit of the recording systems, different spinner groups being recorded, and observer differences in viewing spectrograms (Bazúa-Durán and Au, 2002). Wang et al. (1995a) reported an analysis bandwidth of 0-16 kHz, and Driscoll (1995) and Bazúa-Durán and Au (2002) reported an analysis bandwidth of $0-24 \mathrm{kHz}$. Since whistles with fundamental frequencies extending into the ultrasonic range have been reported for spinner dolphins (Lammers et al., 2003), the recording and analysis bandwidth upper limit has to be high enough to provide complete representations of the vocal repertoire. It is known that descriptive parameters of the whistles, such maximum and ending frequencies, show significant differences between studies conducted with different upper bandwidth limits (Oswald et al., 2004). Lammers et al. (2003) analyzed the acoustic signaling behavior of Hawaiian spinner dolphins in a wider frequency band perspective. The recording system employed allowed them to sample sounds up to $130 \mathrm{kHz}$ and to evaluate the importance of the ultrasonic portion of the sound emissions. Most energy in the fundamental frequency of the whistles was found to be below $24 \mathrm{kHz}$, as Bazúa-Durán and $\mathrm{Au}$ (2002) noted. Based on Lammers et al. (2003) conclusions, we can speculate that the major part of the whistles' fundamental frequencies produced by this species is then taken into account here, since the recording limit used in this study is $24 \mathrm{kHz}$.

It is also known that spinner dolphin whistles can vary geographically (Bazúa-Durán and Au, 2001; Bazúa-Durán et al., 2003; Bazúa-Durán and Au, 2004), as it was already observed for bottlenose dolphins, Tursiops truncatus (Wang et al., 1995b; Jones and Sayigh, 2002), and for the estuarine dolphin, Sotalia guianensis (Azevedo and Van Sluys, 2005). Nevertheless, the factors influencing this observed geographic variation are still unclear, once the pattern found for spinner dolphins does not follow exactly those observed for the other two species. Studying bottlenose dolphins, Wang et al. (1995b) noted that differences in whistle structure were greater between far separated than closer areas. They claimed that, presumably, dolphins in nonadjacent areas have developed unique acoustic characteristics due to geographic isolation. Similarly, Azevedo and Van Sluys (2005), when studying Sotalia guianensis, found that the magnitude of the whistles characteristics variation was comparatively smaller between adjacent sites areas than between nonadjacent ones, although in some pairwise comparisons the result was the opposite.

When comparing spinner dolphins whistles from the Hawaiian Islands (Midway Atoll, Kaua'i, O’ahu, Lãna'i, Maui, and Hawai'i) and from Mo'orea, French Polynesia, BazúaDurán and Au (2002) found that the macrogeographic variation (between Midway and Mo'orea, and the main Hawaiian
Islands) was larger than microgeographic variation (between the main Hawaiian Islands). The authors also found that the variation within each main Hawaiian Island was larger than the variation between them, suggesting the existence of a whistle-specific subgroup (Bazúa-Durán and Au, 2001; Bazúa-Durán and Au, 2004). On the other hand, when the spinner dolphin whistles from the Hawaiian Islands and Mo'orea were compared to the whistles produced by the Tropical Eastern Pacific (TEP) spinner dolphins, greater differences were found between Midway and TEP and Mo'orea groups. O'ahu groups were very similar to TEP and Mo'orea groups, suggesting that there are no differences between oceanic and coastal spinner dolphin whistles. Bazúa-Durán and $\mathrm{Au}$ (2002) claimed that the distinctiveness of Midway whistles could be due to the stability of the spinner dolphins in that area, and that the geographic differences found may not occur solely due to geographic isolation, and that other factors, such as fluidity of the spinner dolphin groups may be also affecting this variation (Bazúa-Durán et al., 2003).

In order to evaluate the variability of spinner dolphin whistles from the Fernando de Noronha Archipelago off Brazil (considered as S. longirostris longirostris), we conducted a series of quali- and quantitative analyses, which are presented here. No other study on this topic has been done in the Southwestern Atlantic Ocean. Moreover, we used available literature data and some statistical tools to investigate the relationship between our results and those obtained in previous studies, looking for any pattern of geographic variation.

\section{METHODOLOGY}

Recordings were made in a bay named "Baía dos Golfinhos," located at the Archipelago of Fernando de Noronha ( $3^{\circ} 51^{\prime}$ 'S and $\left.32^{\circ} 25^{\prime} \mathrm{W}\right)$, Brazil (Fig. 1). The "Baía dos Golfinhos" is an intangible inlet inside the National Marine Park of Fernando de Noronha, where regular access of people and boats is prohibited. This bay carries its name because it is visited daily by spinner dolphins, providing an invaluable site for performing acoustic recordings.

The sound samples were collected on free diving sessions in the "Baía dos Golfinhos" from 4 October to 27 December 2002. Underwater behavioral and acoustic data were recorded using a system composed by a SONY ${ }^{\circledR}$ PD150 digital camcorder housed in an AMPHIBICO ${ }^{\circledR}$ VHPD0150 underwater case equipped with dual external hydrophones. All the recordings were made using a sampling rate of $48 \mathrm{kHz}$, i.e., the frequency upper limit was $24 \mathrm{kHz}$.

The recordings were imported to an Apple ${ }^{\circledR}$ Macintosh computer using the software IMOVIE 4.0.1. (Apple Computer, Inc.). This application breaks the simultaneous audio and video data into clips accordingly to the data code registered in the digital tape, resulting in a different clip per take. This is very important because each take may correspond to a different context or situation. The audio was then extracted from the video files using the software FINALCUT PRO 3.0 (Apple Computer, Inc.), and stored as AIFF format files. CANARY ${ }^{\circledR}$ V.1.2.4 analysis software (Bioacoustics Research Program, Cornell Lab of Ornithology) was used to generate the spectrograms, with a FFT size of 1024 points, an overlap 


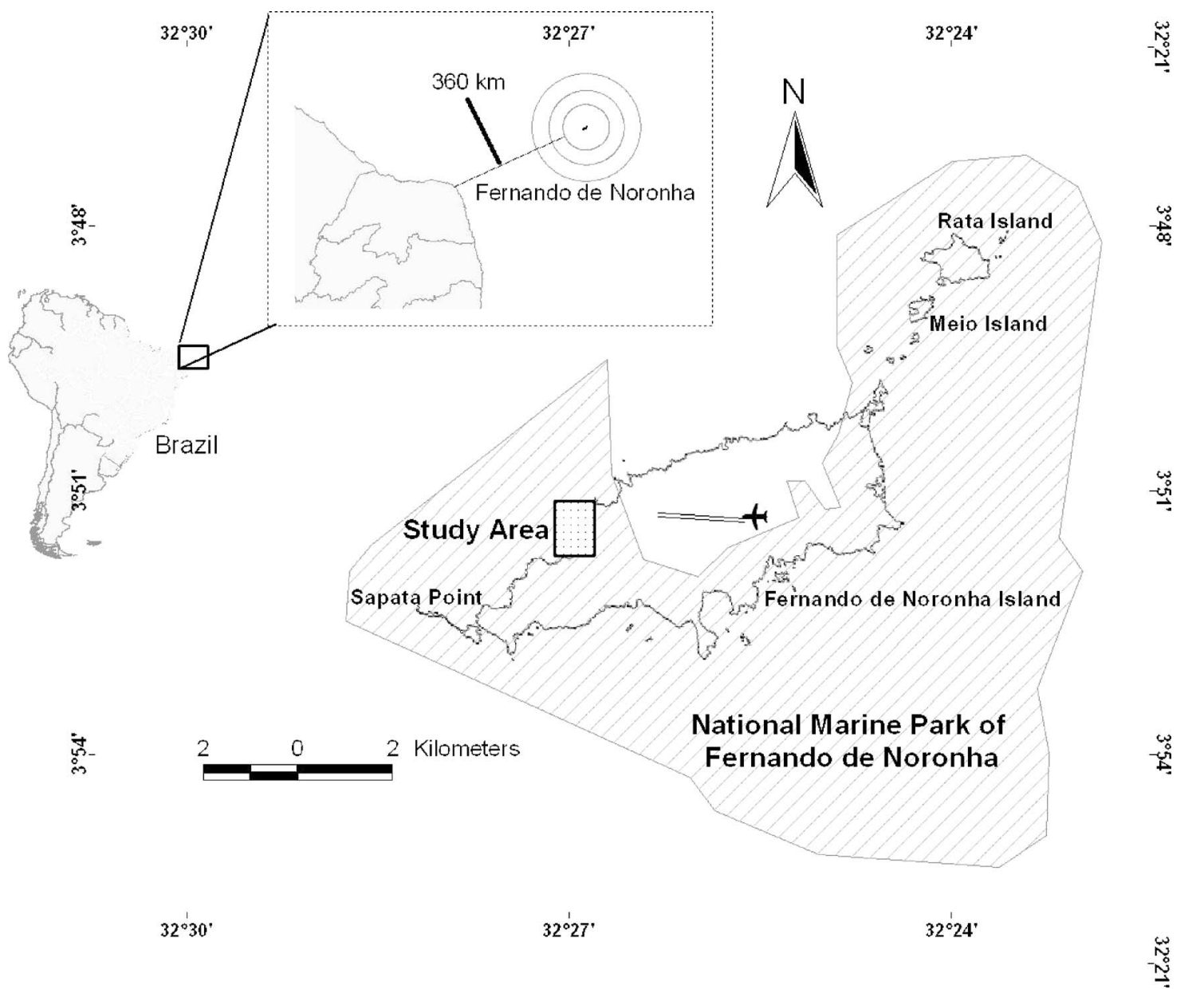

FIG. 1. Map of the study site. The "Baía dos Golfinhos" is situated in the small rectangular inset in the main island of the Fernando de Noronha.

of $50 \%$, a frame length of 512 points, and using a smooth Hamming window. We only used whistles for which all parameters of the spectral contour were distinctly measured and that were not cut off by the upper limit of the recording system (Bazúa-Durán and Au, 2002; Azevedo and Van Sluys, 2005).

From each whistle contour, we extracted nine variables: (1) Beginning frequency (BF), (2) ending frequency (EF), (3) maximum frequency (MAF), (4) minimum frequency (MIF), (5) duration (DUR), (6) number of inflection points (defined as a change from positive to negative or negative to positive slope) (NI), (7) number of breaks (defined as an abrupt variation in frequency in a specific point in time) (NBR), (8) number of loops (a loop was defined as a region where the whistle assumed a parabolic-like shape) (NLO), (9) number of harmonics below the upper frequency limit of the recording system (NHA). These variables were chosen because they can be easily measured from a spectrogram and most of them were chosen to be consistent with the majority of the previous studies with the species, being useful for comparisons.

We also classified the whistle contour into the seven categories described in Driscoll (1995) and Bazúa-Durán and $\mathrm{Au}$ (2002), which were used during the comparison process with previous studies: (1) Upsweep, (2) downsweep, (3) concave, (4) convex, (5) constant, (6) sine, and (7) chirps.
In an exploratory phase, a principal component analysis (PCA) was used as an effort to find variables unimportant to explain data variability so that they could be excluded from the analyses. Preliminary results showed that the two first components of this analysis explained only $66 \%$ of the variability, and only in the sixth component $90 \%$ of the variability was achieved and all variables were already included in the previous components. This implies that any of the variables chosen could not be excluded from the analysis.

Following this step, still as an exploratory analysis, a cluster analysis named CLARA (Clustering Large Applications) (Kaufman and Rousseeuw, 2005) was performed to determine the existence of any grouping pattern of data according to their similarities. The groups formed were then tested with the Silhouette width test (Kaufman and Rousseeuw, 2005), which measures the average dissimilarity between point $i$ and all other points of the cluster, which $i$ belongs to. The CLARA analysis revealed that the whole sample of spinner dolphin whistles could be clumped together into four or five groups, and the Silhouette width test resulted in a score of 0.23 and 0.22 , respectively. None of these results can be considered as a good grouping (Kaufman and Rousseeuw, 2005), and does not seem to have any biological meaning, therefore, not discussed in the present study. 
TABLE I. Descriptive analysis of the whistles (mean, standard deviation, minimum, and maximum values, and variation coefficients). Legend: BF-initial frequency; EF—ending frequency; MIF_-minimum frequency; MAF_-maximum frequency, SP_frequency range; DUR—duration; NI-number of inflection points, NBR—number of breaks, NLO—number of loops, NHA-number of harmonics, nd=not reported.

\begin{tabular}{|c|c|c|c|c|c|c|c|c|c|c|c|c|}
\hline Study & Statistics & $\mathrm{N}$ & $\begin{array}{c}\mathrm{BF} \\
(\mathrm{kHz})\end{array}$ & $\begin{array}{c}\mathrm{EF} \\
(\mathrm{kHz})\end{array}$ & $\begin{array}{c}\mathrm{MIF} \\
(\mathrm{kHz})\end{array}$ & $\begin{array}{l}\text { MAF } \\
(\mathrm{kHz})\end{array}$ & $\begin{array}{c}\mathrm{SP} \\
(\mathrm{kHz})\end{array}$ & $\begin{array}{c}\text { DUR } \\
(\mathrm{ms})\end{array}$ & NI & NBR & NLO & NHA \\
\hline \multirow[t]{5}{*}{ This Study } & Mean & 702 & 10.78 & 12.74 & 9.03 & 14.48 & 5.44 & 495 & 1.16 & 0.86 & 0.66 & 0.63 \\
\hline & Min & 702 & 2.06 & 2.03 & 2.03 & 3.30 & 0 & 1.25 & 0 & 0 & 0 & 0 \\
\hline & Max & 702 & 23.08 & 22.52 & 19.36 & 23.08 & 16.6 & 1800 & 6 & 12 & 4 & 3 \\
\hline & Std Dev. & 702 & 4.08 & 4.02 & 2.79 & 3.87 & 3.44 & 394.69 & 1.15 & 1.72 & 0.77 & 0.67 \\
\hline & C. V. & 702 & 37.88 & 31.54 & 30.85 & 26.73 & 63.20 & 79.78 & 99.17 & 198.28 & 116.48 & 106.97 \\
\hline \multirow[t]{4}{*}{ Wang et al. (1995a) } & Mean & 271 & 10.61 & 14.05 & 9.03 & 15.20 & $n d$ & 750 & 1.07 & $n d$ & nd & nd \\
\hline & Min & 271 & 3.91 & 7.19 & 3.91 & 8.75 & $n d$ & 100 & 0 & $n d$ & nd & $n d$ \\
\hline & Max & 271 & 18.92 & 22.46 & 14.38 & 22.46 & $n d$ & 1820 & 9 & $n d$ & $n d$ & nd \\
\hline & Std Dev. & 271 & 3.44 & 2.37 & 2.24 & 1.66 & $n d$ & 330 & 1.19 & $n d$ & nd & $n d$ \\
\hline \multirow[t]{4}{*}{ Bazúa-Durán and Au (2002) } & Mean & 961 & 12.02 & 14.91 & 10.68 & 16.50 & 5.82 & 449 & $n d$ & $n d$ & 0.42 & $n d$ \\
\hline & Min & 961 & 2.58 & 2.29 & 1.99 & 2.66 & 0.39 & 28 & $n d$ & $n d$ & 0 & $n d$ \\
\hline & Max & 961 & 22.90 & 24.00 & 18.34 & 24.00 & 16.93 & 2256 & nd & $n d$ & 12 & nd \\
\hline & Std Dev. & 961 & 3.66 & 3.80 & 2.68 & 3.54 & 3.67 & 372 & $n d$ & $n d$ & 0.75 & $n d$ \\
\hline \multirow[t]{4}{*}{ Oswald et al. (2003) } & Mean & 112 & 10.40 & 12.40 & 9.10 & 13.70 & 4.6 & 600 & 1.9 & $n d$ & $n d$ & $n d$ \\
\hline & Min & 112 & $n d$ & $n d$ & $n d$ & $n d$ & $n d$ & $n d$ & $n d$ & $n d$ & $n d$ & $n d$ \\
\hline & $\operatorname{Max}$ & 112 & $n d$ & $n d$ & $n d$ & nd & $n d$ & $n d$ & $n d$ & $n d$ & nd & $n d$ \\
\hline & Std Dev. & 112 & 3.40 & 3.60 & 2.50 & 3.50 & 3.40 & 400 & 4.1 & $n d$ & nd & nd \\
\hline \multirow[t]{4}{*}{ Steiner (1981) } & Mean & 2088 & 9.76 & 13.17 & 8.76 & 14.32 & $n d$ & 430 & 0.55 & nd & nd & $n d$ \\
\hline & Min & 2088 & $n d$ & nd & $n d$ & $n d$ & $n d$ & $n d$ & $n d$ & $n d$ & $n d$ & nd \\
\hline & $\operatorname{Max}$ & 2088 & $n d$ & $n d$ & $n d$ & $n d$ & nd & $n d$ & $n d$ & $n d$ & $n d$ & $n d$ \\
\hline & Std Dev. & 2088 & 3.51 & 3.10 & 2.62 & 2.76 & $n d$ & 330 & 0.97 & $n d$ & $n d$ & $n d$ \\
\hline \multirow[t]{4}{*}{ Driscoll (1995) } & Mean & 965 & 11.80 & 14.46 & 10.19 & 16.80 & $n d$ & 661 & $n d$ & $n d$ & nd & $n d$ \\
\hline & Min & 965 & 4.64 & 4.00 & 4.00 & 5.60 & $n d$ & 40 & $n d$ & $n d$ & $n d$ & $n d$ \\
\hline & $\operatorname{Max}$ & 965 & 21.44 & 23.04 & 21.22 & 23.04 & $n d$ & 1870 & $n d$ & $n d$ & $n d$ & $n d$ \\
\hline & Std Dev. & 965 & 3.66 & 3.91 & 2.40 & 3.17 & $n d$ & 334 & $n d$ & $n d$ & $n d$ & $n d$ \\
\hline \multirow[t]{4}{*}{ Lammers et al. (2003) } & Mean & 167 & $n d$ & nd & 10.10 & 17.40 & 7.3 & 660 & nd & $n d$ & nd & 1.83 \\
\hline & Min & 167 & $n d$ & $n d$ & $n d$ & $n d$ & $n d$ & $n d$ & nd & $n d$ & $n d$ & nd \\
\hline & Max & 167 & nd & $n d$ & $n d$ & $n d$ & $n d$ & $n d$ & $n d$ & $n d$ & $n d$ & $n d$ \\
\hline & Std Dev. & 167 & $n d$ & $n d$ & 2.50 & 3.0 & 3.9 & 330 & $n d$ & $n d$ & $n d$ & 0.87 \\
\hline
\end{tabular}

To compare the mean values obtained for the frequency and time parameters with the results presented in previous studies, we applied a series of univariate and multivariate tests, using the Program "R" (R Development Core Team, 2004). First, we used Levene's $F$ test to evaluate the homogeneity of variances. Later, we used the $t$ test for homogeneous variances and Welch's $t$ test for nonhomogeneous variances so as to compare the means (the mean of each variable observed in this study and the correspondent mean found in other studies, as described in the literature).

We also used a classification method through a multivariate statistic test in order to identify which of the results presented in earlier studies would be closer to the results found here. We considered, as a classification criterion, the minimum distance between each value observed in this study and the mean for each of the variables obtained for each other study included in the comparison, weighted for the inverse of the covariance matrix. The distance was defined as

$$
D_{j}=\left(\mathbf{y}-\overline{\mathbf{y}}_{j}\right)^{t} \mathbf{S}_{j}^{-1}\left(\mathbf{y}-\overline{\mathbf{y}}_{j}\right)
$$

Where the $D j$ is the minimum distance, $y$ represents each value for the variable $j$ found in this study and $\bar{y}_{j}$ is the mean value presented in the earlier studies for the variable $j$. This method is complementary to the T Test in comparison between different populations, and allowed us not only to compare means but also to better visualize which population is closest to the Fernando de Noronha population.

Finally, in order to investigate differences in the categorization of whistles between the present study, and in the Driscoll (1995) and Bazúa-Durán and Au (2002) studies, we used the Pearson's $X$-squared statistic.

\section{RESULTS AND DISCUSSION}

\section{A. Frequency and time parameters}

A summary of the descriptive statistics (mean, minimum, maximum, standard deviation, and variation coefficients) of all frequency and time parameters for the 702 whistles included in the analysis is shown in Table I. Our analysis showed that the mean $\mathrm{BF}$ was lower than the mean 
TABLE II. Correlation matrix of the whistle frequency and time parameters observed in this study, considering. Legend: BF-Initial frequency; EF-Ending frequency; MIF-Minimum frequency; MAF-Maximum frequency; DUR—Duration.

\begin{tabular}{lccccc}
\hline \hline & BF & EF & MIF & MAF & DUR \\
\hline BF & 1.00000000 & $0.2458209^{\mathrm{a}}$ & $0.7204156^{\mathrm{a}}$ & $0.5735262^{\mathrm{a}}$ & 0.04887347 \\
$\mathrm{EF}$ & $0.24582094^{\mathrm{a}}$ & 1.0000000 & $0.5053420^{\mathrm{a}}$ & $0.7370411^{\mathrm{a}}$ & $0.14147378^{\mathrm{a}}$ \\
MIF & $0.72041564^{\mathrm{a}}$ & $0.5053420^{\mathrm{a}}$ & 1.0000000 & $0.4896629^{\mathrm{a}}$ & $-0.14251817^{\mathrm{a}}$ \\
MAF & $0.57352625^{\mathrm{a}}$ & $0.7370411^{\mathrm{a}}$ & $0.4896629^{\mathrm{a}}$ & $1.0000000^{\mathrm{a}}$ & $0.41746774^{\mathrm{a}}$ \\
DUR & 0.04887347 & $0.1414738^{\mathrm{a}}$ & $-0.1425182^{\mathrm{a}}$ & $0.4174677^{\mathrm{a}}$ & 1.00000000 \\
\hline \hline
\end{tabular}

${ }^{a}$ Significant correlation at the 0.01 level.

EF, as it had already been observed by Bazúa-Durán and Au (2002). On average, whistle spanning times were relatively short, with mean values around $0.495 \mathrm{~s}(\mathrm{SD}=0.79 ; \mathrm{N}=702)$. We also conducted an analysis of the degree of association between all variables by using a Correlation Matrix, which is shown in Table II. A significant association was observed between all variables, excluding BF and DUR, which were shown to be independent. The greatest correlation values were observed between $\mathrm{BF}$ and MIF $(r=0.720, P=0.01)$, and $\mathrm{EF}$ and MAF $(r=0.737, P=0.01)$. Both were positively correlated, indicating that when one of these variables increases its value, the other does the same. We also observed a small negative correlation between MIF and DUR $(r=-0,142, P$ $=0.01$ ), indicating that when the minimum frequency increases, the duration of the whistle decreases.

The parameters of whistle frequency and time had the lowest variation coefficient of all analyzed variables (Table I), and they were, therefore, treated separately. Furthermore, these variables are present in all previous studies conducted with spinner dolphin whistles, which allown us to perform a series of comparisons, as shown below. From the parameters of frequency and time, those associated with frequency had lower variation coefficients when compared to the duration, indicating that the time parameter is more variable, as it has already been observed for Sotalia guianensis (Azevedo and Van Sluys, 2005). For S. longirostris, Steiner (1981), Wang et al. (1995a), and Oswald et al. (2003) also found a lower value of variation coefficients for frequency parameters, with the exception to the frequency range, which exceed the duration's one in the third study.

As a first effort of inserting our results in the literature context, we conducted a $t$ Test, and the results are shown in Table III. The study of Oswald et al. (2003) presented less significant differences in relation to ours; with only whistle duration differing significantly between both works.

Later, in order to find which of the earlier studies on populations of spinner dolphins would have the closest results to those obtained in Fernando de Noronha, we conducted a classification test (according to the criteria of minimum distance described above). It is important to take into account that, as we did not have the variance and covariance matrices observed in the earlier studies, we performed the classification test assuming three possibilities of different matrices: (1) All variables being independent (i.e., the corre-

TABLE III. Comparison of the values obtained in this study with the results presented in the available literature to each of the considered whistle variables.

\begin{tabular}{|c|c|c|c|c|c|c|c|}
\hline \multirow[t]{3}{*}{$\mathrm{BF}$} & $t$ Test & 0.655 & $-6.389^{a}$ & 1.066 & $5.927^{\mathrm{a}}$ & $-5.260^{\mathrm{a}}$ & - \\
\hline & $\begin{array}{l}\text { Degrees of } \\
\text { Freedom }\end{array}$ & 577.295 & 1411.277 & 166.470 & 1070.988 & 1410.47 & - \\
\hline & $p$-value & 0.513 & $<0.001$ & 0.288 & $<0.001$ & $<0.001$ & - \\
\hline \multirow[t]{2}{*}{$\mathrm{EF}$} & $t$ Test & $-6.263^{\mathrm{a}}$ & $-11.223^{\mathrm{a}}$ & 0.843 & $-2.587^{\mathrm{a}}$ & $-8.763^{\mathrm{a}}$ & - \\
\hline & $\begin{array}{l}\text { Degrees of } \\
\text { Freedom }\end{array}$ & 815.406 & 1661 & 812 & 995.950 & 1665 & - \\
\hline \multirow[t]{3}{*}{ MIF } & $t$ Test & 0 & $-12.187^{\mathrm{a}}$ & -0.250 & $2.252^{\mathrm{a}}$ & $-8.881^{\mathrm{a}}$ & $-4.540^{\mathrm{a}}$ \\
\hline & $\begin{array}{l}\text { Degrees of } \\
\text { Freedom }\end{array}$ & 606.459 & 1661 & 812 & 1149.498 & 1370.121 & 867 \\
\hline & $p$-value & 1 & $<0.001$ & 0.803 & 0.025 & $<0.001$ & $<0.001$ \\
\hline MAF & $t$ Test & $-4.056^{\mathrm{a}}$ & $-10.895^{\mathrm{a}}$ & 2.001 & 1.012 & $-13.021^{\mathrm{a}}$ & $-10.646^{\mathrm{a}}$ \\
\hline \multirow{2}{*}{ DUR } & $\begin{array}{l}\text { Degrees of } \\
\text { Freedom }\end{array}$ & 582.619 & 1661 & 812 & 1049.19 & 1353.577 & 290.452 \\
\hline & $p$-value & $<0.001$ & 0.015 & $<0.001$ & $<0.001$ & $<0.001$ & $<0.001$ \\
\hline
\end{tabular}

${ }^{\mathrm{a}}$ The mean difference is statistically different at the 0.05 level. 
TABLE IV. Classification of the observations according to the distance (the numbers mean the amount of whistles that had the minimum distance value from each variable observed in this study and the correspondent mean value of each study).

\begin{tabular}{|c|c|c|c|c|c|c|}
\hline Matrix of Variance-Covariance & Wang et al. $1995 \mathrm{a}$ & Bazúa-Durán and Au 2002 & Oswald et al. 2003 & Steiner 1981 & Driscoll 1995 & Total \\
\hline Independent & 26 & 196 & 278 & 84 & 118 & 702 \\
\hline $\begin{array}{l}\text { With Variance-Covariance } \\
\text { Matrix equal to the one } \\
\text { observed in this study }\end{array}$ & 103 & 170 & 119 & 223 & 87 & 702 \\
\hline $\begin{array}{l}\text { With the Variances } \\
\text { presented in each study and } \\
\text { the same correlations } \\
\text { observed in this study }\end{array}$ & 1 & 0 & 701 & 0 & 0 & 702 \\
\hline
\end{tabular}

lation is zero), (2) variance and covariance matrices being equal to those observed in this study, (3) combining the variances presented in each study together with our correlation. The result of this classification can be observed in Table IV. As in the univariate analysis, we had a concentration of minor distances in the study of Oswald et al. (2003) in two situations: When we considered the variable set independent and when we used the true variances, presented in each study, together with our correlations. However, when we assumed the matrix exactly equal to the one presented in our study, the concentration of minor distances moved to Steiner, 1981 (Table IV).

There are many problems when comparing different efforts. At first, the methods and equipment used to record the sound samples were sometimes distinct. In this study, we recorded the animals during free diving. Although this apparently does not disturb the animals, changing their natural behavior can interfere in their communication process. The earlier studies recorded in the presence of a boat, which can also cause alterations. Moreover, recording equipments were not equal, and varied in the upper frequency limit of the recording system. In the majority of studies, the upper frequency limit of the recording system was greater than $22 \mathrm{kHz}$ (with sample rates of 44.1 or $48 \mathrm{kHz}$ ), with the exception to the Wang et al. (1995a) study, who used a system with an upper frequency limit of around $16 \mathrm{kHz}$. Differences in the whistle selection and in the sample size could also conduct to different results.

Additionally, we have to consider that animals engaged in different activities during the recording sessions, as well as being present in different group sizes, can have a significant influence in the sound emission of the group envelope (for example, Norris et al., 1994; Herzing, 2000). BazúaDurán and Au (2002), for example, compared their study with Wang et al. (1995a) and Driscoll (1995), which were all made in the same place ("Island of Hawaii"), and found significant differences between them when comparing duration and the same frequency variables analyzed in this study. Nevertheless, in their study of geographic variation of spinner dolphin whistles among the Hawai'ian Islands, BazúaDurán and Au (2004) did not find any significant differences in whistles emmitted by dolphins with behavioral state and pod size.

In spite of all these difficulties what we intended to do here, in addition to presenting insights to the whistle repertoire of spinner dolphins from the Fernando de Noronha Ar- chipelago (which has never been acoustically studied before), was to test if there was some closeness between this population and other ones studied earlier as an attempt to clarify any geographic variation pattern. We judged the results acquired here as very interesting, pondering that our population would supposedly be closer to the Tropical Eastern Pacific population, studied by Oswald et al. (2003). When comparing means, the spinner dolphins from the Fernando de Noronha differ significantly from the TEP only on the duration of the whistles (considering that the variation coefficient of this variable were higher than the frequency ones in both studies). If this is true, the difference in duration could be associated with the recording of different individuals, engaged in different activities, as explained by BazúaDurán and Au (2004) for Hawaiian spinner dolphins, and suggested by Whitten and Thomas (2001) for Lagenorhynchus obliquidens, and by Janik et al. (1994), and Wang et al. (1995b) for Tursiops truncatus. Otherwise, the similarities between populations so disjunct could possibly be attributed to biogeographic reasons, reflecting that these two populations were more recently isolated than the North and South Atlantic populations, being in contact before the formation to the Panama Isthmus. Other studies have made an approach to this question, although using coastal teleost fishes, such as those of Tringali et al. (1999), Craig et al. (2004), and Craig et al. (2006). In the case of spinner dolphins, such a question is beginning to be addressed (Farro et al., 2005).

Heeding to the results of the classification test, we could consider two different types of results. If we suppose that our population should be more similar to the population from North Atlantic, studied by Steiner (1981), when choosing a variance-covariance matrix exactly equal to that obtained in this study, the results would be associated to some degree of information exchange through intermediate groups, as were already observed by Bazúa-Durán and Au (2002) for Hawaiian spinner dolphins, by Wang et al. (1995b) for Tursiops truncatus, and by Azevedo and Van Sluys (2005) for Sotalia guianensis; and the differences between the Fernando de Noronha population and the Pacific Ocean population could be due to geographic isolation. However, we believe that the third option of variance-covariance matrix is the closest to the real one, where the correlation values that compose the matrix are the ones provided by other studies. Using this matrix, the concentration of minimum distances in the study of Oswald et al. (2003) correspond to most of the observations, which confirm the result obtained in the univariate 


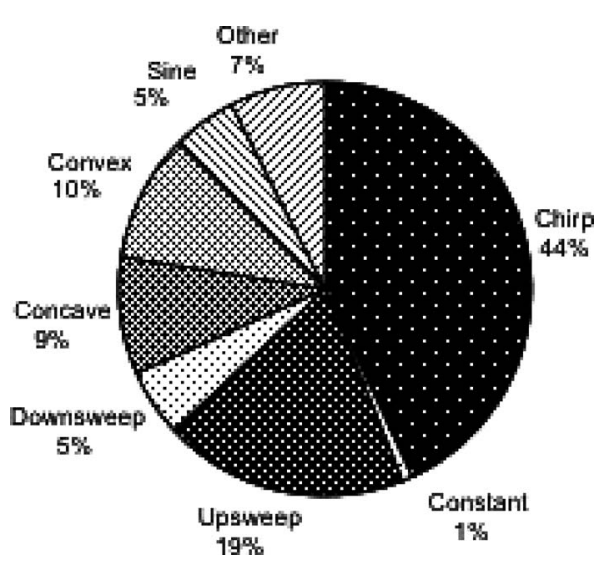

FIG. 2. Distribution of analyzed whistles into categories, being "Other" the category that includes all gradation between other two categories.

analysis and reinforce the idea of proximity between these two populations.

\section{B. Whistle contour}

Taking the contour variables of the whistles into consideration, we noticed that all of them (number of breaks, number of inflection points, number of loops, and number of harmonics) have a higher variation coefficient than the frequency and time parameters, as it is shown in Table I. This was already been observed in the studies of Steiner (1981), Wang et al. (1995a), and Oswald et al. (2003), especially for the number of inflection points and the number of harmonics (when it appears as a whistle parameter). This high intraspecific variability may be a result of individual modulation, transmitting information about identity or context (BazúaDurán and Au (2004); Azevedo and Van Sluys, 2005), or the directionality of the emissive animal, in the specific case of number of harmonics (Lammers et al. 2003).

Regarding the classification in categories and according to the contour shape of the whistles in the spectrograms, $7 \%$ of the whistles could not be ascribed to any of the categories created by Driscoll (1995) and Bazúa-Durán and Au (2002), because they looked like a gradation between two other categories. These whistles were thus set in a category named "Other," as is shown in Fig. 2. This new category is very heterogeneous in the whistle contours that were classified here, and must be reevaluated in the near future. With the aim of comparing the whistles categories distribution found here with the distributions presented by Driscoll (1995) and
Bazúa-Durán and Au (2002), we excluded all the assemblage of whistles ascribed to this new category, as it is shown in Fig. 3.

The distribution of the whistles grouped into categories is different between the present study and each of the previous ones (Driscoll, 1995; Bazúa-Durán and Au (2002)), at least in the percentage of two categories, as it is shown by the results of the Pearson's $X$-squared statistic test in Table $V$. However, the two categories of whistles more frequently recorded, "Chirps" and "Upsweep" were not significantly different between our study and the one of Bazúa-Durán and $\mathrm{Au}$ (2002). The "Constant" category, which was very rare, is not significantly different between the three studies. Further, the whistle category "Sine" is very abundant in the studies of Driscoll (1995) and Bazúa-Durán and Au (2002), while it was not in the present study. We believe that this situation occurred because we set a great number of whistles that could have been called by these authors as "Sine," in the "Other" category, due to the great variability of this kind of whistle shape.

Although other authors have shown that whistles have a graded nature and that categorization have not been, therefore, a precise way to represent a repertoire of a given species or population of dolphins, we used it as an additional available resource of comparison between different populations, as it was suggested by Bazúa-Durán and Au (2002). The results are interesting due to the similarity in the general distribution of the whistles in all categories, especially between our study and that of Bazúa-Durán and Au (2002), from which we differed only in two categories, "Sine" and "Concave" (see Fig. 3 and Table V). The comprehension of the significance of these similarities is still difficult due to the lack of biological meaning of this categorization.

We firmly believe that more accurate studies comparing different populations and using more controlled sources of bias should be conducted and are fundamental to achieve this knowledge. Studies focusing in the correlation of sound production and the individual dolphin associated with, should also be conducted, taking into account characteristics such as sex, age class, and behavior.

\section{CONCLUSIONS}

Acoustic characteristics of the whistles emitted by dolphins have been described and quantified in a number of studies, and have shown to be useful during comparisons
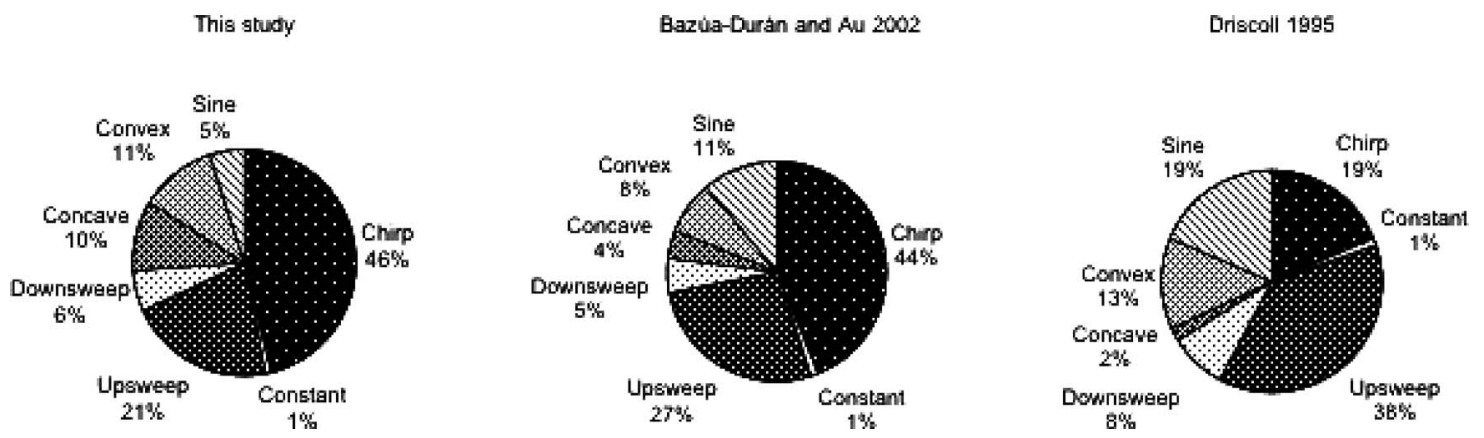

FIG. 3. Comparison of the whistle distribution in the seven categories described by Driscoll (1995) and Bazúa-Durán and Au (2002). 
TABLE V. Comparison of the percentage of whistles ascribed to the seven categories with the correspondent results presented by Bazúa-Durán and Au (2002) and Driscoll (1995).

\begin{tabular}{lcccc}
\hline \hline & $\begin{array}{c}\text { Bazúa-Durán and Au, 2002 } \\
\text { Pearson's } \\
\text { X-squared } \\
\text { statistics }\end{array}$ & $p$-value & $\begin{array}{c}\text { Driscoll, } 1995 \\
\text { Pearson's } \\
\text { Categoryared } \\
\text { statistics }\end{array}$ & $p$-value \\
\hline Sine & $18.077^{\mathrm{a}}$ & $<0.001$ & $23.535^{\mathrm{a}}$ & $<0.001$ \\
Convex & 3.993 & 0.046 & $12.277^{\mathrm{a}}$ & $<0.001$ \\
Concave & $22.945^{\mathrm{a}}$ & $<0.001$ & 5.953 & 0.015 \\
Downsweep & 0.608 & 0.435 & $6.642^{\mathrm{a}}$ & $<0.001$ \\
Upsweep & 7.581 & 0.006 & $26.054^{\mathrm{a}}$ & $<0.001$ \\
Constant & 0.000 & 1 & 0 & 1 \\
Chirp & 0.578 & 0.447 & $138.373^{\mathrm{a}}$ & $<0.001$ \\
\hline \hline
\end{tabular}

${ }^{\mathrm{a}}$ The mean difference is statistically different at the 0.05 level.

between groups and populations, as during categorization of different species (for instance, see Steiner, 1981; Wang et al., 1995a and 1995b; Bazúa-Durán and Au, 2002, 2004; Oswald et al. 2004). In this context, the description presented here, as well as the comparisons conducted with the results available in the literature for other populations, contributes to this huge effort of knowing how populations are organized geographically, and which characteristics of whistles are important to differentiate populations and/or species. Increasing the effort on bioacoustical studies for other known populations of spinner dolphins would allow us to better recognize the existence of any pattern of geographic variation and its correlation to biological features, and these in turn could help to ascribe, in a better resolution, the taxonomic status of each population and subspecies.

\section{ACKNOWLEDGMENTS}

We thank Lawrence Wabba, Guillian Buhl, and Alice Grossman for the help and support during different phases of the fieldwork. We also thank Melina Baumgarten and Luis Fábio Silveira for their important comments and for reviewing earlier versions of the manuscript, and the two anonymous reviewers who have made insightful suggestions for improving the manuscript. We also thank CAPES and Projeto TAMAR for the financial and logistical support and IBAMA for giving the necessary permits to data collection inside the National Marine Park of Fernando de Noronha.

Akin, P. A. (1988). "Geographic variation in tooth morphology and dentinal patterns in the spinner dolphin, Stenella longirostris," Marine Mammal Sci. 4(2), 132-140.

Azevedo, A. F., and Van Sluys, M. (2005). "Whistles of tucuxi dolphins (Sotalia fluviatilis) in Brazil: Comparisons among populations," J. Acoust. Soc. Am. 117(3), 1456-1464.

Barlow, J. (1984). "Reproductive seasonality in pelagic dolphins (Stenella spp.): Implications for measuring rates," Rep. Int. Whal. Comm. 6, 191198.

Bazúa-Durán, C., and Au, W. L. (2001). "Geographic variation in whistles of spinner dolphins (Stenella longirostris)," $14^{\text {th }}$ Biennial Conference on Biology of Marine Mammals, Vancouver, Canada, 28 Nov.-3 Dec.

Bazúa-Durán, C., and Au, W. L. (2002). "The whistles of Hawaiian spinner dolphins," J. Acoust. Soc. Am. 112(6), 3064-3072.

Bazúa-Durán, C., and Au, W. L. (2004). "Geographic variations in the whistles of spinner dolphins (Stenella longirostris) of main Hawaiian Islands," J. Acoust. Soc. Am. 116(6), 3757-3769.

Bazúa-Durán, C., Au, W. L., and Oswald, J. N. (2003). "Possible reasons for the geographic variations in the whistles of spinner dolphins (Stenella longirostris) of the Pacific Ocean," $17^{\text {th }}$ Conference of the European Cetacean Society, Las Palmas de Gran Canaria 9-13 March.

Craig, M. T., Hastings, P. A., and Pondella, D. J. (2004). "Speciation in the Central American seaway: The importance of taxon sampling in the identification of trans-isthmian geminate pairs," J. Biogeogr. 31, 1085-1091.

Craig, M. T., Hastings, P. A., Pondella, D. J., Ross Robertson, D., and Rosales-Casián, J. A. (2006). "Phylogeography of the flag cabrilla Epinephelus labriformis (Serranidae): Implications for the biogeography of the Tropical Eastern Pacific and the early stages of speciation in a marine shore fish," J. Biogeogr. 33, 969-979.

Douglas, M. E., Schnell, G. D., Hough, D. J., and Perrin, W. F. (1992). "Geographic variation in cranial morphology of spinner dolphins Stenella longirostris in the Eastern Tropical Pacific Ocean," Fish. Bull. 90, 54-76. Driscoll, A. D. (1995). The whistles of Hawaiian spinner dolphins, Stenella longirostris. Master's thesis, University of California at Santa Cruz.

Farro, A. P. C., Rollo, M. M. Jr., Silva, J. M. Jr., and Marino, C. L. (2005). "Skin sampling for genetic analysis of a South Atlantic spinner dolphin (Stenella longirostris) population," in 16th Biennial Conference on Biology of Marine Mammals, 2005, San Diego, CA. (Abstract).

Gray, J. E. (1828). Specilegia Zoologica; or Original Figures and Short Systematic Description of New and Unfigured Animals, Treuettel, Wurtz and Wood, London.

Herman, L. H., and Tavolga, W. N. (1980). "The communication system of cetaceans" in Cetacean Behavior: Mechanisms and Functions, edited by L. H. Herman (Wiley, New York), pp. 149-209.

Herzing, D. L. (2000). "Acoustics and social behavior of wild dolphins: implications for a sound society" in Hearing by Whales and Dolphins, edited by W. W. L. Au, A. N. Popper, and R. F. Fay (Springer Verlag, New York), pp. 225-272.

Janik, V. M. (2000). "Source levels and the estimated active space of bottlenose dolphin (Tursiops truncatus) whistles in the Moray Firth, Scotland," J. Comp. Physiol. 186, 673-680.

Janik, V. M., and Slater, P. J. B. (1998). "Context-specific use suggests that bottlenose dolphin signature whistle are cohesion calls," Anim. Behav. 56(4), 829-838.

Janik, V. M., Dehnhardt, G., and Todt, D. (1994). "Signature whistle variation in the bottlenosed dolphin, Tursiops truncatus," Behav. Ecol. Sociobiol. 35(4), 243-248.

Jones, G. J., and Sayigh, L. S. (2002). "Geographic variation in rates of vocal production of free-ranging bottlenose dolphin," Marine Mammal Sci. 18(2), 374-393.

Kaufman, L., and Rousseeuw, P. J. (2005). Finding groups in data: An introduction to cluster analysis, (Wiley, New York), pp. 342.

Lammers, M. O. and Au, W. L. (2003). Directionality in the whistles of Hawaiian spinner dolphins (Stenella longirostris): A signal feature to cue direction of movement?, Marine Mammal Science, 19(2), pp. 249-264.

Lammers, M. O., Au, W. L., and Herzing, D. L. (2003). "The broadband social acoustic signaling behavior of spinner and spotted dolphins," J. Acoust. Soc. Am. 114(3), 1629-1639.

McCowan, B., and Reiss, D. (1995). "Maternal Aggressive contact vocalizations in captive bottlenose dolphins (Tursiops truncatus): Wide-band, low-frequency signals during mother/aunt-infant interactions," Zoo Biol. 14, 293-309.

McCowan, B., and Reiss, D. (2001). "The fallacy of 'signature whistles' in bottlenose dolphin: A comparative perspective of 'signature information' in animal vocalizations," Anim. Behav. 62, 1151-1162.

Norris, K. S., Wursig, B., Wells, R. S., and Wursig, M. (1994). The Hawaiian Spinner Dolphin, (University of California Press, Berkeley), p. 408.

Oswald, J. N., Barlow, J., and Norris, T. F. (2003). "Acoustic identification of nine delphinid species in the eastern tropical Pacific Ocean," Marine Mammal Sci. 19(1), 20-37.

Oswald, J. N., Rankin, S., and Barlow, J. (2004). "The effect of recording and analysis bandwidth on acoustic identification of nine delphinidae species," J. Acoust. Soc. Am. 116(5), 3178-3185.

Perrin, W. F. (1990). "Subespecies of Stenella longirostris (Mammalia: Cetacea: Delphinidae)," Proc. Biol. Soc. Wash. 103, 453-463.

Perrin, W. F., Akin, P. A., and Kashiwada, J. V. (1991). "Geographic variation in external morphology of the spinner dolphin Stenella longirostris in the Eastern Pacific and implications for conservation," Fish. Bull. 89, 411-428.

Perrin, W. F., and Dolar, L. L. (1996). "Preliminary results on spinner dolphins, Stenella longirostris, from Philippines," IBI Rep. 6, 25-33.

Perrin, W. F., Dolar, M. L. L., and Robineau, D. (1999). "Spinner dolphins 
(Stenella longirostris) of the Western Pacific and Southeast Asia: Pelagic and shallow water forms," Marine Mammal Sci. 15(4), 1029-1053.

Perryman, W. L., and Westlake, D. (1998). "A new geographic form of the spinner dolphin, Stenella longirostris, detected with aerial photogrammetry," Marine Mammal Sci. 14(1), 38-50.

R Development Core Team (2004). "R: A language and environment for statistical computing," Vienna, Austria, R Foundation for Statistical Computing. http://www.R-project.org. Last accessed 11/10/06.

Steiner, W. W. (1981). "Species-specific differences in pure tonal whistle vocalizations of five Western North Atlantic dolphin species," Behav Ecol. Sociobiol. 9, 241-246.

Tringali, M. D., Bert, T. M., Seyoum, S., Bermingham, E., and Bartolacci, D. (1999). "Molecular Phylogenetics and Ecological Diversification of the Transisthmian Fish Genus Centropomus (Perciformes: Centropomidae)," Mol. Ecol., 13, 193-207.

Tyack, P. L. (1998). "Acoustic Communication under sea," in Animal Acoustics Communication-Sound Analysis and Research Methods, edited by S. L. Hopp, M. J. Owen, and C. S. Evans (Springer-Verlag, New York), pp. 163-219.

Van Waerebeek, K. V., Gallagher, M., Baldwin, R., Papastravrou, L., and Al-Lawati, S. M. (1999). "Morphology and distribution of the spinner dolphin, Stenella longirostris, rough-toothed dolphin, Steno bredanensis and melon-headed whale, Peponocephala electra, from waters off the Sultanate of Oman," J. Cetacean Res. Manage. 1(2), 167-177.

Wang, D., Wursig, B., and Evans, W. (1995a). "Comparison of whistles among seven odontocete species," in Sensory systems of Aquatic Mammals, edited by R. A. Kastelein, J. A. Thomas, and P. E. Nachtingall (The Spil Publishers, Woerden, The Netherlands), pp. 299-323.

Wang, D., Wursig, B., and Evans, W. (1995b). "Whistles of bottlenose dolphins: Comparison among populations," Aquat. Mamm. 21(1), 65-77.

Whitten, J. L., and Thomas, J. A. (2001). "Whistle repertoire of Pacific white-sided dolphins (Lagenorhynchus obliquidens) at the John G. Shedd Aquarium,” J. Acoust. Soc. Am. 109, p. 2391. 